Marcello Giovanelli*

\title{
Construing and reconstruing the horrors of the trench: Siegfried Sassoon, creativity and context
}

https://doi.org/10.1515/jls-2019-2009

\begin{abstract}
Cognitive Grammar has emerged in recent years to become an established analytical method in cognitive stylistics. Although one of its key affordances is that it provides a robust framework for analysing the different ways in which scenes can be depicted, researchers have yet to develop an account of how Cognitive Grammar can support a detailed analysis of authorial creativity. This paper aims to redress the balance by using Cognitive Grammar to examine the relationship between creativity and the unique situations that give rise to writing in a diary entry and two subsequent rewritings of that entry by the First World War poet and soldier Siegfried Sassoon. The paper combines ideas on contextual constraints with a text-driven, Cognitive Grammar-oriented analysis to demonstrate how a contextualized approach highlights the ways in which Sassoon's writing is motivated by particular physical, social and cultural environments. These include the interaction with and reconfiguration of the material body within the physical setting of the military trench.
\end{abstract}

Keywords: Cognitive Grammar, construal, Siegfried Sassoon, creativity, context

\section{Introduction}

In a letter to his pacifist friend Lady Ottoline Morrell in October 1917, the First World War soldier and poet Siegfried Sassoon included the poem 'Death's Brotherhood'. At that time, Sassoon had been hospitalized for neurosis at Craiglockhart Hospital after he had made a much-discussed declaration against the war. In a note that appeared at the end of the letter, he remarks that 'This poem will show you what I feel like. And it is the truth' (Sassoon 1983: 191). In fact, 'Death's Brotherhood' is largely based on an earlier diary entry 'In the ward ii' (Sassoon 1983), written when Sassoon, having been wounded in action, was recuperating in London in April 1917. Intriguingly, 'In the ward ii' was also revised for Sassoon's autobiographical novel Memoirs of An Infantry Officer

*Corresponding author: Marcello Giovanelli, School of Languages and Social Sciences, Aston University, Birmingham, UK, E-mail: m.giovanelli@aston.ac.uk 
(Sassoon 1930, hereafter Infantry Officer). There are therefore three separate, and creatively distinct, versions of the same series of events.

This paper explores the connections between these versions through the lens of Langacker's (1987, 1991, 2008) Cognitive Grammar (henceforth CG). Specifically, I use CG to provide an analysis of how Sassoon presents the scene in his diary entry of April 1917 and then later re-presents the same details in two quite different genres and situations. This paper also aims to integrate a CG analysis into Kövecses' (2015) model of contextual motivation to examine how the immediate context of Sassoon's experience of war might be read as licensing the various options he has available to him for representing his experiences. In doing so, I argue that this integrated approach can help to interpret Sassoon's representations as motivated by the particular physical, social and cultural environments in which they were conceived. In the first instance these contexts incorporate Sassoon's interaction with the landscape of the trench and his consequent representations of the human body. In his later poetry and prose, I examine how further types of context may be understood as giving rise to the ways in which scenes are presented.

\section{Construal, reconstrual and intentionality}

An important claim in CG is that the meaning of an expression relies both on the conceptual content it evokes and on how that content is presented. Speakers and writers draw on a number of construal phenomena (Langacker 2008: 55-59) to present a conceived scene, which may include selecting a degree of specificity, focusing attention on one aspect that is foregrounded against a neglected background, imposing more dynamic or static conceptualisations of a scene, and providing a particular kind of viewing arrangement or vantage point from which a situation is presented. A fundamental premise of construal is that the selection of various lexical choices and grammatical configurations that frame the presentation of conceptual content, whether undertaken consciously or unconsciously by a conceptualising agent, is principled, motivated and meaningful, and reflects our basic experience of moving, perceiving and acting in the world (Langacker 2008: 4).

A reconstrual is a specific type of retelling that diverts a listener or reader's attention at a later date through some further manipulation of any of the construal operations. Reconstruals may, for example, increase or decrease specificity, foreground some previously downplayed aspect of 
content, present a scene in a more or less dynamic way or reconfigure some part of the viewing arrangement so as to impose a different perspective. Indeed since any content contains the potential for numerous, alternative realizations through the situated selection of different lexical and grammatical choices by a conceptualiser (Croft 2001), reconstruals may be thought of more generally as the foregrounding of a construal that had been previously neglected. The fact that construals are conceptualiser-driven and, therefore socially-oriented and context-bound, means that it should be possible to account for possible motivations for both the initial construal and for any subsequent reconstruals in a systematic way.

Since any one construal can be understood as a matter of choice (Langacker 2008: 55) or as the organization and packaging of conceptual content (Evans and Green 2006: 536), they are evidence of authorial creativity and textual design; reconstruals of writing consequently are evidence of writerly reconfiguration of content and various degrees of intensification or reduction (Sotirova 2014: 147). West (2017), however, notes that literary applications of CG have yet to fully examine construal in terms of authorial creativity in any significant detail. Conversely, construal and reconstrual have been examined from the readerly end of the communication dyad (Forrest 1996; Harrison 2017; Browse 2018; Nuttall 2018; Harrison and Nuttall 2019).

The reasons for a lack of focus on the production end of communication appear straightforward since stylisticians have tended to be wary of the theoretical naivety associated with biographical speculation and of assigning intentionality to literary discourse. However, as Sotirova (2014: 138) notes, studying the process of revision itself demands that authorial intentions are treated seriously; for Sotirova, it is impossible to engage in any discussion of revision without placing an authorial figure at the heart of that production process. This is also a stance taken by Herman (2013). Arguing against a reaction by structural narratologists to the intentional fallacy (Wimsatt and Beardsley 1946), Herman critiques the division of an authorial figure into 'real' and 'implied' versions (Booth 1961) and consequent models of narrative communication (e.g. Chatman 1978) on the basis that such a divide misaligns a reified, and superfluous entity (the implied author) with what is essentially an inferential process. Instead, drawing on research from a range of disciplines that demonstrates the human tendency to assign causes of acting to events, Herman argues for a theoretical model that proposes that readers infer reasons for authorial decisions from 'defeasible, context-bound ascriptional practices' (Herman 2013: 62). In a similar way, Stockwell $(2009,2016,2017)$ argues that readers mind-model authorial figures, investing in them intentions and a range of attributes and behaviors, drawing on the general cognitive ability to build mental representations of 
others, fictional or otherwise. Both Herman and Stockwell therefore recognize the author as part of 'the texture of literature' (Stockwell 2016: 161), whilst acknowledging 'the readerliness of authorial intention modeling' (Stockwell 2016: 153) and the 'variability in ascriptive practice' (Herman 2013: 68) that different readers will assign. Their work provides a usable framework that avoids the interpretative cul-de-sac the analyst may face when attempting to deal with the conundrum of accounting for the presence of a creative source without resorting to claims of telepathy or certainty regarding intention. As Sotirova (2014) argues, such a framework also replicates models of spoken communication with their emphases on co-ordinated joint action and the co-negotiation of meaning discourse, as well as more broadly being aligned to attentional models of language (e.g. Clark 1996; Marchetti 2006). The importance of authorial design is highlighted in sociolinguistic research on the retelling of stories (e.g. Polanyi 1981). And, Lambrou (2014) demonstrates how, when revising stories, speakers assimilate new narratives into older ones on the basis of perceived importance and relevance. Speakers thus retell and arrange stories so that they are 'tailored for the occasion' (Lambrou 2014: 36).

In this paper I integrate Kövecses' $(2005,2015)$ work on the influence of context into my text-driven CG analysis in order to examine and account for the licensing of authorial creativity. That is, I ascribe reasons for authorial decisions in line with what seem to me salient contextual factors that appear to constrain potential construal operations. Furthermore, I argue CG, with its ability to account explicitly for various ways in which experience can be represented, provides a welcome analytical apparatus for examining First World War poetry, a genre that has largely come to be almost always defined and situated in relation to its historical moment (Winter 2014), and which is usually read through a contextual lens. In fact, it is generally difficult to find literary-critical material that examines war poetry outside of its immediate biographical, cultural and historical contexts (see for example Thorpe 1966; Moeyes 1997; Campbell 1999 on Sassoon; and, more broadly, individual chapters on Sassoon, Owen, Rosenberg and Jones in Das 2013).

\section{Context: embodiment and creativity}

Recent work in cognitive science, psychology and linguistics has stressed the influential role of context on creativity and linguistic expression. For example, Barrett et al. (2005: 5) arguing for the 'context principle', posit that all mental events emerge from the environment symbiotically through a series of transactional 
processes that emphasize the relationship of mind and thought to the body and its surroundings. Indeed creativity itself can be understood as both a 'dynamic process' and a 'completed product' (Carter 2011: 340) that arises from the interaction between a mind with an intention to create and the specific sociocultural contexts that shape and influence that intention (Rothenberg 1990; Csikszentmihaly 1997). Within cognitive psychology and linguistics, one manifestation of the mind-context relationship is the principle of embodied cognition (Lakoff and Johnson 1999; Gibbs 2005). Taking embodiment seriously means acknowledging how the inherent and immediate physical and social contexts that the human body is placed in directly influence cognition and provide structures that allow for the organization and representation of the world through language.

In his critique of a universalist view of embodiment, however, Kövecses (2005, 2008, 2015) argues for a broader and more sensitive treatment of social, cultural and historical variation; his theory of 'differential experiential focus' (Kövecses 2005) posits that different contextually-driven aspects of embodiment may be drawn on by groups or individuals to trigger and structure metaphorical mappings. In Kövecses (2015), he argues that contextual factors have a 'priming effect' (2015: 49) and sanction the selection of a particular source domain, providing a theoretical and practical framework that separates out more 'basic' embodied influences from those that are triggered by specific contextual factors; the latter give rise to what he terms 'context induced creativity' (2015: 99). In the process of conceptualizing content, he argues that conceptualisers are faced with a pair of oppositional forces that offer different degrees of strength and may therefore impact on the conceptualizer in varying ways:

Conceptualisers try to be coherent both with their bodies (their basic embodied experiences) and their contexts (the various contextual factors) where the body and context function as, sometimes conflicting, forms of constraint on conceptualization. The outcome of the two pressures depends on which influence, or pressure, turns out to be the stronger in particular situations. Kövecses (2015: 51)

These various contextual factors (further differentiated in terms of being global or local) are summarized (Kövecses 2015: 184, 186) as follows:

- the situational context: including the physical, social and cultural settings;

- the discourse context: the surrounding discourse, including the co-text;

- the conceptual-cognitive context: the memories, domains and knowledge and ideologies held by individuals and groups.

- the body context: the explicit and immediate sense of the body in space.

In his final context type, Kövecses suggests that a more radical sense of the body may override primary and basic notions of embodiment. That is, the body may 
act in more local and idiosyncratic ways to license particular construals. Although Kövecses focuses on metaphor in his study, there seems to be no reason why such a context schema might not be used to examine the motivation for other kinds of construal, given that metaphor is one type of construal operation (Croft and Cruse 2004: 55). Consequently, I argue that Kövecses' model is useful for examining the motivation for and licensing of construal operations more generally, and that recognition and discussion of these contextual factors may give insights into how these construals are understood and interpreted.

Indeed in his comprehensive discussion of the importance of touch in First World War poetry, Das (2005) highlights the body as a specific and important local context. Das demonstrates that many of those who experienced the war at the Front both drew on and represented reconfigured senses of the body in their writing. In the trenches, the physical landscape, an abundance of mud and the restricted use of artificial light at night meant that touch became an important communicative register for soldier-writers. In this haptic world, conceptual motivation and licensing - and therefore creativity - derive from immediate embodied experience, from the realignment of the body and the foregrounding of touch, and from the transformation of the human form. Das supports his argument by drawing on the sheer volume of references to horizontal, animalistic movement in various forms of writing from the Front to suggest that the geography of the trenches reconfigured the body from a conventional vertical schema to a horizontal one. This shift provided an immediate local context for the motivation of particular representations of experience as Das (2005: 44) explains.

The absolute lowering of the body on the ground allies seeing with the 'baser senses' of touch and smell. The trench mud thus challenged the vertical organization of bodily Gestalt, and marked a regression to the clumsy horizontality of beasts. Rat, mole, earthworm and snail are recurrent similes that are used in trench narratives to describe the soldiers.

My first analysis of Sassoon's representation of experience in his first diary entry is informed by this initial observation. It aims to account for Sassoon's construal of the scene relayed in the diary entry by combining a CG-led analysis with an appeal to wider contextual motivations. My later analyses draw on a similar method to account for the differences evident in Sassoon's revisions to his earlier material and thus aim to provide a contexualised account of the process of reconstrual. I therefore argue that it is possible to identify textual patterns that demonstrate how experiences and content are variously magnified, downplayed or substituted for previously occluded content. I argue that as well as 
acknowledging default (Croft and Cruse 2004: 72) construals of experience, it is possible to ascribe more explicit, local and textually-retrievable contexts that can be understood as licensing more idiosyncratic construals and can be used as part of the process of ascribing intentionality to textual revisions.

\section{Construing and reconstruing war experience: From diary entry to prose memoir}

\section{1 'In the ward ii'}

'In the ward ii' is a diary entry that Sassoon composed on either the 24th or the 25th April 1917 during his stay at Denmark Hill Hospital, London. In this section, I examine a short passage (reproduced below) in which Sassoon describes a vision he had late at night.

And, when the lights are out, and the ward is half shadow and half glowing firelight, and the white beds are quiet with drowsy figures, huddled out-stretched, then the horrors come creeping across the floor: the floor is littered with parcels of dead flesh and bones, faces glaring at the ceiling, faces turned to the floor, hands clutching neck or belly; a livid grinning face with bristly moustache peers at me over the edge of my bed, the hands clutching my sheets. (Sassoon 1983: 161)

Sassoon's earlier diary entries in April 1917 provide a useful background to 'In the ward ii'. They largely recount his movement along the Front, where, when not marching, long periods of time were spent in either trenches or tunnels. Entries leading up to his injury of 16th April make repeated reference to his inability to sleep and to the mass of dead and mutilated bodies, variously described as 'lying by the road' (1983: 153), 'lying about the trenches and in the open' (1983: 154), 'in various states of dismemberment' (1983: 155) and 'shelltwisted' (1983: 155). Given that these entries appear just before 'In the ward ii', they provide a significant discourse context for the reader to make thematic connections across the diary entries as a whole.

In CG, the concept of specificity relates to the level of detail in which a scene is construed. For example a group of people may be construed in a schematic, general manner using the noun phrase 'a crowd' or in turn, with increasing specificity, as 'people', or 'my friends', or 'my friends from when I worked in Nottingham' and so on. Each successive instance provides more detail, elaborating (Langacker 2008: 55) the former expression and providing a greater granularity that results in a sharper resolution. Using a visual analogy, increased 
resolution results in a construal that foregrounds the finer details of a scene and backgrounds more schematic ones. Turning to 'Into the ward ii', we can see that the noun 'figures' presents a relatively schematic construal where discrete and identifying physical features are downplayed in favour of a more uniform and schematic mass; even the pre-modifying adjective 'drowsy' fails to prevent the construal from being a very general one. This pattern, with its distinctive lack of elaboration, continues across the extract. The description of the bodies of the soldiers who appear in the vision similarly lacks specificity. The noun 'horrors' is schematic enough to imply a depersonalized account of the scene as is the metaphor 'parcels of dead flesh'; 'flesh' is a more coarse-grained construal in reference to the body than 'arm' or 'leg' or 'skin and hair'. Within the same noun phrase, however, 'bones' begins a series of more specific construals, maintained in 'faces glaring', faces turned', 'hands clutching', 'neck or 'belly' all of which now offer a more fine-grained view of the scene and lead to the complex noun phrase 'a livid grinning face with grinning moustache' that forms the final, chilling and highly specific image of the opening vision. In turn, the physical setting of the scene itself becomes more finely-grained from the low resolution inherent in the noun phrase 'half-shadow and half glowing firelight' to the more sharply-focused 'my bed' and 'my sheets', where the possessive determiners clearly designate the owner of 'bed' and 'sheets' and thus construe specific instances of a broader category or type (Langacker 2008: 267). In these two examples, the noun phrases offer a less schematic representation of the scene and the possessives foreground the narrator's position and role in the unfolding events.

The ways in which the soldiers are construed, both alive and dead, emphasize the horizontal nature of their bodies. The use of the past participle 'outstretched', the deictic verb 'come creeping' and the prepositional phrase 'across the floor' all invite the reader to scan the bodies of the figures in a horizontal dimension, the latter two suggesting movement towards the speaking deictic centre. This movement combines with increased granularity along the spatial plane since the complex preposition 'across' construes a more textured view of the floor that adds to the scene the dimension of width to that of length (compare this to 'along the floor' which would simply denote a path of movement). The construal offered by 'across' magnifies our view of the scene so that the movement of the 'horrors' brushing against the material of the floor as they move becomes visible (see Croft and Cruse 2004: 52 for discussion of differing spatial construals). Even the projected viewpoint of the figures is constrained by the horizontal schema: the faces look down or orient their gaze upwards from their prostrate position.

The conceived scene thus far is one where prominence is given to horizontality and an increase in granularity towards the image of the 'livid grinning face', 
construed in all its horror. In addition, a pattern emerges in terms of how the scene is variously scanned. In CG, sequential scanning involves 'mentally tracking an event as it unfolds through time' (Langacker 2008: 111) so that the reader follows the real-time and discrete moments in the event; typically this type of scanning is realized through the use of finite verbs that profile parts of a process one after another. Alternatively, an event that has all of its states integrated into a 'single gestalt comparable to a multiple-exposure photograph' (Langacker 2008: 111) is scanned in a more summative fashion. In this instance, the use of non-finite verb forms or nominals imposes summary scanning on conceptual content.

In 'In the ward ii', the sentence predication in the initial description 'And, when the lights are out, and the ward is half shadow and half glowing firelight, and the white beds are quiet with drowsy figures' means that the scene is initially scanned sequentially. However, there are a number of participial forms that follow, which either act adjectivally as in the past participles 'huddled, outstretched' or else form non-finite clauses, as in the present participles glaring' and 'clutching'. Participles impose summary scanning on verb processes and atemporalise them; in the case of past participles, the construal imposed is of a fixed state whilst for present participles only one internal aspect of a longer process is profiled (Langacker 2008: 120). In this extract, the shift from sequential scanning to largely summary scanning (and indeed from the stative-adjectival function of the past participles to the internal vantage point afforded by the present participial forms) increases the sense of perceived proximity to the scene (see also Verspoor 1996; and Giovanelli 2014 for an effect of this kind of construal in Sassoon's poetry).

Overall, the stylistic pattern in this extract consists of an increase in specificity, an emphasis on horizontality, and the imposition of largely summary scanning which promotes heightened proximity and intensity. It is thus possible to attribute some kind of intentionality to this pattern through the licensing contextual factors that may be read as influential. In Kövecses' terms these include the immediate body context, which we infer as Sassoon's exposure to the horrors of the trenches and tunnels, their reshaping and destruction of the human body and Sassoon's repeated mention of insomnia and bad dreams. An interpretation of Sassoon's construals is enriched through consideration of the discourse context, for example in this striking description that appears in his diary just before 'In the ward ii'. Here it is not difficult to connect the image of the mud-stained hands to the ghostly hands of the vision in 'In the ward ii'.

[...] two mud-stained hands were sticking out of the wet ashen chalky soil, like the roots of a shrub turned upside down. They might have been imploring aid; they might have been groping and struggling for life and release [...] (Sassoon 1983: 159) 


\subsection{Memoirs of an infantry officer}

Infantry Officer represents a very different type of writing to a diary entry not least because Sassoon adopts a fictional persona, George Sherston, as his narrator. ${ }^{1}$ Aside from the understandable change in tense (as a retrospective narrative, Infantry Officer is in the past tense), many of the differences between the two versions are subtle. I therefore place the two descriptions side-by-side in Figure 1 for ease of analysis. Similar and/or reconstrued parts of both extracts are numbered and in bold.

'In the ward ii’ (1983: 161-162)

And, when the lights are out, and 1. the ward is half shadow and half glowing firelight, and 2. the white beds are quiet with drowsy figures, huddled out-stretched, then 3 . the horrors come creeping across the floor: 4 . the floor is littered with parcels of dead flesh and bones, 5 . faces glaring at the ceiling, faces turned to the floor, hands clutching neck or belly; 6. a livid grinning face with bristly moustache peers at me over the edge of my bed, the hands clutching my sheets.
Memoirs of An Infantry Officer (1930: 248)

I was being worried by bad dreams. More than once I wasn't sure whether I was awake or asleep; 1 . the wards were half shadow and half sinking firelight, and 2 . the beds were quiet with huddled sleepers. 3. Shapes of mutilated soldiers came crawling across the floor; 4. the floor seemed to be littered with fragments of mangled flesh. 5. Faces glared upwards; hands clutched at neck or belly; 6. a livid grinning face with bristly moustache peered at me above the edge of my bed; his hands clawed at the sheets.

Figure 1: 'In the ward ii' and Infantry Officer

In revising his diary entry, Sassoon makes a number of authorial interventions. The introductory subordinate clause of 'In the ward ii', 'when the lights are out' is replaced with two framing sentences that foreground the fact that the narrator here is dreaming. The narrative of Infantry Officer is thus deictically remote from the initial framing narration, forming a discrete dreamworld (Werth 1999) that represents an extreme or nightmare experience (see Giovanelli 2013). Indeed the very end of the full extract from Infantry Officer is as follows.

1 Although Sherston's experiences of the war largely equate to those detailed by Sassoon in his diaries, an obvious omission in Infantry Officer is the reference to any literary interest: Sherston is not a poet and Infantry Officer has no mention of the experience of writing that permeates the diaries nor does it include any verse. 
Violently awake, I saw the ward without its phantoms. The sleepers were snoring and a nurse in grey and scarlet was coming silently along to make up the fire. (Sassoon 1930: 248)

Here, 'Violently awake' triggers a shift from the dream state to the parameters of the waking world, the 'sleepers', the 'nurse in grey and scarlet' and 'the fire'. In 'In the ward ii', however, the narrator ends by exclaiming 'I wish I could sleep' (Sassoon 1930: 162), clearly construing the conceived scene described as a waking experience, albeit one that is closer to a hallucination.

Like most representations of literary dreams, the transition into the dreamworld in Infantry Officer is explicitly announced, 'bad dreams', and modalised, 'I wasn't sure', to foreground the narrator's uncertainty regarding the conceived scene. Within the dream itself, further modality is also present: 'the floor seemed to be littered'. In CG, modalised constructions are analysed as part of a model of reality in which scenes are presented in relation to degrees of knowledge about the world. Modalised constructions are indices of projected or potential reality, which stand at some distance from conceived or immediate reality (Langacker 2008: 306). Modality also imposes a more subjective construal (Langacker 2008: 77) on a scene in which, using the analogy of watching a play, a conceptualizer self-positions 'on stage' as part of the focus of attention. In contrast, in a more objective construal, attention is simply on the scene being described. In 'In the ward ii', the scene remains objectively construed until the mention of the possessive determiners in 'my bed [...] my sheets' positions the narrating conceptualizer on stage providing a more subjective construal. In Infantry Officer, however, subjectivity is foregrounded from the beginning through the use of the first person pronoun 'I' and the modality in the framing of the dream.

Further subtle differences emerge when comparing the extracts. Whereas in 'In the ward ii', the narrator talks of 'the ward', in Infantry Officer, the plural form 'the wards' is used. In this case, the move is from a singular instance to a more representative one that is abstracted out from multiple instances to give a more general construal of the scene. The dream-like atmosphere is maintained in the alternative construal of the 'firelight'. In 'In the ward ii', 'half glowing' profiles the relationship between the light and the space above it from bottom to top in an upwards motion and representative of an ongoing state. In Infantry Officer, however, the construal of 'half sinking' means that the relationship is scanned downwards, from top to bottom, emphasizing a greater sense of darkness since 'sinking' implies that the light will soon be extinguished. This feature combines with the framing of the dream, modality and the more abstracted construal of the scene to give the extract its ambience (Stockwell 2014). Arguably, another perceivable effect of this dimming down is that it accounts for the more schematic construal that consequently emerges. In 'In the ward ii', the scene increases in 
granularity to provide a vivid and shocking climax when the dead solider reaches the narrator's bed. In Infantry Officer, the setting is construed more schematically: there is no adjectival modification of the noun phrase 'the bed', 'huddled' is moved from its post-qualifying position in 'In the ward' to become a premodifier of the noun phrase 'sleepers', and the modifiers 'drowsy' and 'outstretched' disappear. Indeed, 'sleepers' highlights the actions of the men in the beds rather than their bodies to emphasize the difference between the narrator and other soldiers on the ward. Although the scene is presented in a more schematic and coarsely grained manner, the bodies of the ghostly soldiers are presented in finer granularity and figured as more salient in the overall construal of the experience. Thus, the greater specificity in 'shapes of mutilated soldiers', with the weight on the partitive construction provides a more finely grained construal than 'the horrors' of 'In the ward'. And, 'mangled flesh' offers greater specificity than 'dead flesh' to convey the physical state of the soldiers.

The verb choices also shift across the two versions:

'In the ward ii': 'come creeping across the floor' and 'the hands clutching my sheets'

Infantry Officer: 'came crawling across the floor' and 'his hands clawed at the sheets'

The construal in Infantry Officer presents a more aggressive and animalistic individual. In turn, the intensity of the dream vision with its vivid focus on the soldier is evident in the more objective construal in Infantry Officer where 'hands' is indirectly rather than directly grounded through the possessive determiner 'his' and subjectivity is temporarily occluded through the use of the definite article in 'the sheets' (in contrast to 'my sheets'). And, the use of 'above' instead of 'over' profiles a different kind of trajectory: in Infantry Officer, the grinning face is construed more summatively, suspended in the air and capable of perennial haunting whilst 'over' profiles a movement from a starting point to the edge of the bed and beyond (see Ungerer and Schmid 2006: 168). In addition, whereas the largely dominant imposition of summary scanning in 'In the ward ii' gives rise to an effect of conceptual proximity, the central parts of the experience are reconfigured in Infantry Officer into processes that are sequentially scanned: 'faces glared upwards; hands clutched at neck or belly'. As these processes are viewed as complete events rather than portions of them, there is a playing down of the immediacy that appeared to be one of the hallmarks of 'In the ward ii'.

As I have argued, accounting for differences between the two extracts means considering a stylistic analysis in conjunction with a serious treatment of context. One of the most important contexts is the genre of Sassoon's writing, 
captured in Kövecses' notion of discourse context. 'In the ward ii' is an entry in a personal diary that initially would not have been written for publication; the reconstrual in Infantry Officer is part of the second book in a planned trilogy with a more clearly defined audience and set of carefully crafted thematic concerns and motifs (see Fussell 2000: 90-105). Sassoon started writing Infantry Officer in the late 1920s and published it in 1930, over ten years after the events described in 'In the ward ii'. The passing of time is evident in how the immediacy of experiences represented in Sassoon's diary is replaced by the natural retrospection of Infantry Officer. This quality of Infantry Officer is recognized in those literary critical responses that have read the Sherston trilogy as less intuitive and reactionary, as a more 'detached' (Thorpe 1966: 106) and 'sanitized' (Campbell 1999: 2) version of the experience of war. This temporal context provides an interpretative frame for several aspects of Sassoon's design: the qualities of a more schematic view of the setting, the greater imposition of sequential scanning and downplaying of the summary form, the abstraction of experience to represent a type rather than a specific instance of the event, and the more consciously modalised constructions with greater subjective construal. These all appear to be more indicative of a rounded, observed retrospect than a more impressionistic portrayal of immediate experience.

A further context offers a means of accounting for the use of the nightmare frame, a prominent textual feature in the Infantry Officer extract. A possible reason for Sassoon's revision of the events on 'In the ward ii' as a nightmare can be ascribed to his experience of being treated by the eminent physician WH Rivers at Craiglockhart Hopsital, their discussions, and Sassoon's later acknowledgement of Rivers' work. ${ }^{2}$ Writing about war dreams in his posthumously published Conflict and Dreams, Rivers (1923: 66) commented:

\begin{abstract}
A characteristic feature [of the war dream] is that it is accompanied by an effect of a peculiarly intense kind, often with a special quality described as different from any known in waking life. The dream ends suddenly by the patient waking in an acute state of terror directly continuous with the threat of the dream and with all the physical accompaniments of extreme fear, such as profuse sweating, shaking and violent beating of the heart. Often the dream recurs in exactly the same form night after night, and even several times in one night, and the sufferer will often keep himself from sleeping again after one experience from dread of its repetition.
\end{abstract}

In this instance, it is tempting to read the extract in Infantry Officer in the conceptual-cognitive context of Sassoon's shifting understanding of war neurosis, his

2 Sassoon had been treated by Rivers and the two later became friends. The first part of Sherston's Progress details their discussions at Craiglockhart and the impact of Rivers' thinking on Sassoon. 
relationship with Rivers and a more detached consideration of the effects of war on the mind than would have been possible in April 1917. This interpretation designates Sherston's narrator as an abstraction of the soldiers who suffered various forms of war neurosis, a reading that is supported both by a text-driven analysis and by the generic affordances, which allow Sherston to be represented in a more detached way and therefore as a more abstract and representational type.

\section{5 'Death's brotherhood'}

'Death's Brotherhood' was published in The English Review in January 1918 and then, later that year, with some very minor alternations, as 'Sick Leave' in Counter-Attack and Other Poems. The poem is reprinted below as it originally appears in Sassoon's letter of October 1917.

\footnotetext{
When I'm asleep, dreaming and drowsed and warm,-1

They come, the homeless ones, the noiseless dead.

While the dim charging breakers of the storm

Rumble and drone and bellow overhead,

Out of the gloom they gather about my bed. 5

They whisper to my heart; their thoughts are mine.

'Why are you here with all your watches ended?

'From Ypres to Frise we sought you in the Line.'

In bitter safety I awake, unfriended;

And while the dawn begins with slashing rain 10

I think of the Battalion in the mud.

'When are you going back to them again?

'Are they not still your brothers through our blood?'
}

(Copyright Siegfried Sassoon by kind permission of the Estate of George Sassoon)

The poem compresses the conceptual content of 'In the ward ii' to foreground a more specific kind of detail: the relationship between the speaker and the visiting ghosts. In a similar way to the extract in Infantry Officer, the poem bears the explicit marking of a dream frame, 'When I'm asleep, dreaming', although the negative aspect of the dream which marked Infantry Officer is omitted. The scene is also subjectively construed from the beginning, like Infantry Officer, but unlike 'In the ward ii'. The high initial schematicity of 'In the ward ii' is replicated in the personal pronoun 'They', which cataphorically references the two noun phrases with near rhyming post-modifying adjectives, 'the homeless ones, the noiseless dead'. However, unlike 'In the ward ii', the construal does not increase in specificity; in fact, the bodies of the soldiers are 
not mentioned at all and any further reference to them as entities is simply through the use of the pronoun 'They' and the possessive determiner 'their'. The low granulation afforded to the soldiers is in contrast to that afforded to the setting. Unlike in Infantry Officer, the setting is construed in greater specificity with an emphasis on the movement and sounds of the storm. Although the horizontal schema, so evident in 'In the ward ii' and Infantry Officer, is entirely omitted, the relative deictic positioning of the soldiers who, 'out of the gloom', move towards the speaker remains the same. Here the ghosts are construed in a way that emphasizes their more sinister presence: the use of the preposition 'about' represents the trajectors (ghosts) completely enclosing the landmark (bed) rather than being positioned at a relative distance from it.

Sassoon's decision to use a dream frame thus gives structure to the entire poem; lines 1-8 consist of the speaker's dream vision ${ }^{3}$ and lines 9-13 revert to the speaker's waking world, likely to be understood as taking place in the hospital ward (here readers drawing on the discourse context are likely to identify the location of the poem as Craiglockhart rather than Denmark Hill Hospital). In lines 5-6, the pattern of pronouns suggests that the ghosts of 'Death's Brotherhood are closer to the speaker, unlike the soldiers in 'In the ward ii' and Infantry Officer, who initially appear to haunt the speaker from a distance. The repetition of 'They...my'/'their...mine' in 'Death's Brotherhood' highlights this proximity: in line 7 the ghosts later point, using the proximal deictic 'here', to the speaker's closeness to them but to his remoteness to soldiers that are still alive and serving in France. The dream ends with the waking clause 'I awake' prefaced by the adverbial 'In bitter safety'. The disappearance of the ghosts alters the state of the speaker's now 'unfriended' mind in waking consciousness. The disarming nature of the ghosts' visit is evident in the emotional and physical distance the speaker now feels: the specific construal offered in the noun phrase 'slashing rain' contrasts with the more schematic, remote landscape, realized in the prepositional phrase 'in the mud'.

Assigning a voice to the final two lines remains somewhat problematic. Framed within speech marks, lines 12-13 appear to mirror the direct speech of lines 7-8 and could be a continuation of the ghosts' words albeit in the speaker's waking rather than dream state. Equally, the reporting clause 'I think' could legitimize a reading that places these words as the speech/thought of the speaker. In these competing readings, different prominence is assigned depending on the referents we choose to assign to the pronouns 'you', 'them' and 'they' and the possessive determiners 'your and 'our'. In CG, pronouns (and their derivatives) may be used with varying degrees

3 There is a further remote world-switch initiated by the direct speech of the soldiers, which provides a more complex conceptual structure than either 'In the ward ii' or Infantry Officer. 
of delimitation (Langacker 2007), referring to the extent to which a pronoun designates a smaller (high delimitation) or larger (low delimitation) set of referents. In 'Death's Brotherhood', 'you' and 'your' appear to be highly delimited since their referent is the poem's speaker both in a reading that assigns the lines to the ghosts and to one that assigns them to the speaker. The situation with 'them/they' is similar. Regardless of how we assign the final lines, 'them/they' appear highly delimited (the referents here are the speaker's fellow soldiers). It is possible, however, to read these pronouns with lower delimitation: 'them/they' may have the broader referents of soldiers in general. The case with 'our' is more complex. Assigning the lines to the ghosts means that 'our' designates a larger group (to include the ghosts, the speaker and the men still in France) whilst assigning the lines to the speaker designates a smaller group of just the speaker and his men (excluding those who are now dead). The ambiguity perhaps also rests on whether we read 'blood' literally (the blood of the ghosts) or at a more symbolic level, as a schema that connects speaker and soldiers. Deciding on who speaks these lines also means deciding on the organization of the end of the poem: assigning the lines to the ghosts means integrating them into a sudden flashback to the dream via a world-switch that may be read simply as a fleeting one or else leaves the speaker deictically stranded from the opening of the poem.

The kinds of complexities I have been discussing can also be seen in literary-critical responses to the poem that suggest Sassoon's guilt and a growing tension between adhering to his original pacifism and a sense of duty to the men he commanded influenced the writing of the poem. For example, Thorpe (1966: 29) argues that the poem deals with 'the betrayal of comradeship' and Campbell (1999: 104) posits that the poem represents 'a figurative encapsulation of the tension he [Sassoon] is having to deal with'. I believe any interpretation of the poem is enriched by reading it in this contextualised manner and by accounting for specific construal operations in the light of the various situational, discourse and conceptual-cognitive contexts that surround the production of the poem. Indeed the complexity of the poem is evident in the fact that it appears in a letter to Ottoline Morrell, a well-known influence on and sympathizer with Sassoon's anti-war sentiment, and that elsewhere in the letter there are conflicting indications of both his desire to return to the Front and his unswerving commitment to pacifist principles. Sassoon (1983: 190) writes:

[...] I have told Rivers that I will not withdraw anything that I have said or written, and that my views are the same, but that I will go back to France if the War Office will give me a guarantee that they will really send me there [...] After all I made my protest on behalf of my fellow fighters and (if it is a question of being treated as an imbecile for the rest of the war) the fittest thing for me to do is to go back and share their ills. 
I think that this duality of sentiment is central to the poem and to understanding how it differs in its complexity from the arguably more basic construals of experience in 'In the ward ii' and in Infantry Officer. The construal in 'Death's Brotherhood' with its clear focus on the framing of the dream, the detailed description of the speaker's waking state, its more ambiguous representation of ghosts, and its manipulation of the pronoun system is more nuanced. The ghosts here are, it seems, a more finely-tuned and realized representation of an inner turmoil in the speaker. In short, as in Infantry Officer, Sassoon abstracts actual instances of soldiers into a virtual instance, this time to present a more personal and focused representation of a mind that is torn between two sets of principles (see for example Hipp 2005: 165 for a literary-critical analysis of this idea).

\section{Conclusion}

In this paper, I have argued that contextualizing these three separate versions of the same event offers a way of understanding the creative energies behind the retelling of events. This paper has also argued that CG's notions of construal and reconstrual provide a systematic way of examining the production end of the communicative chain as part of a fully contextualized yet text-driven stylistic practice. Integrating CG as an analytical method with Kövecses' model of different contextual constraints thus offers a way of combining text-driven analysis with legitimate enquiry into the various influences of extra-textual events. In 'In the ward ii', an understanding of Sassoon's construals can be enriched by considering the degree to which preceding events, captured in his diary, provide a discourse context and by the way in which the construal of the body might be read in light of the spatial parameters of the trenches and tunnels at the Front. The later reconstruals of this initial depiction can be examined in a similar way, using Kövecses' framework, through the conceptual-cognitive and situational contexts of Sassoon's time at Craiglockhart and his possible shifting concerns between 1917 and 1930 .

It is therefore possible to approach reconstruals as the motivated, principled, linguistic realizations of other potential ways of shaping content. A contextualized stylistic account thus allows the sensible discussion of those motivations as a way of demonstrating 'how literary intention can be brought back into our discussion and interpretation of literature without thereby compromising the accuracy of the linguistic analysis that formalism can offer' 
(Sotirova 2014: 138). In doing so it provides a way of considering the kinds of construal constraints that influence and license creative practice. ${ }^{4}$

\section{References}

Booth, W. 1961. The rhetoric of fiction. Chicago: University of Chicago Press.

Browse, S. 2018. From functional to cognitive grammar in stylistic analysis of Golding's The Inheritors. Journal of Literary Semantics 47(2). 121-146.

Campbell, P. 1999. Siegfried Sassoon: A study of the war poetry. Jefferson, NC: Macfarland. Carter, R. 2011. Epilogue - creativity: Postscripts and prospects. In J. Swann, R. Pope \& R. Carter (eds.), Creativity in language and literature: The state of the art, 334-344. Houndmills, Basingstoke: Palgrave Macmillan.

Chatman, S. 1978. Story and discourse: Narrative structure in fiction and film. Ithaca: Cornell University Press.

Clark, H. 1996. Using language. New York, NY: Cambridge University Press.

Croft, W. 2001. Radical construction grammar: Syntactic theory in typological perspective. Oxford: Oxford University Press.

Croft, W. \& D.A. Cruse. 2004. Cognitive linguistics. Cambridge: Cambridge University Press.

Czikszentmihaly, M. 1997. Creativity: The psychology of discovery and invention. New York, NY: HarperCollins.

Das, S. 2005. Touch and intimacy in first world war literature. Cambridge: Cambridge University Press.

Das, S. (ed.) 2013. The Cambridge Companion to the Poetry of the First World War. Cambridge: Cambridge University Press.

Evans, V. \& M. Green 2006. Cognitive linguistics: An introduction. Edinburgh: Edinburgh University Press.

Feldman Barrett, L., B. Mesquita \& E.R. Smith. 2005. The context principle. In L. Feldman Barrett, B. Mesquita \& E. R. Smith (eds.), The mind in context, 1-24. New York, NY: The Guildford Press.

Forrest, L.B. 1996. Discourse goals and attentional processes in sentence production: The dynamic construal of events. In A. Goldberg (ed.), Conceptual structure, discourse and language, 149-161. Stanford, CA: CSLI.

Fowler R. 1977. Linguistics and the novel. London: Methuen.

Fussell, P. 2000. The great war and modern memory, 2nd edn. Oxford: Oxford University Press. Gibbs, R. 2005. Embodiment and cognitive science. New York, NY: Cambridge University Press. Giovanelli, M. 2013. Text world theory and Keats' poetry: The cognitive poetics of desire, dreams and nightmares. London: Bloomsbury.

4 I am grateful to one of the anonymous reviewers of this article for highlighting that a further construal constraint in terms of authorial creativity is the fact that Sassoon uses English, a satellite-framed language where the manner of motion is presented in the verb (e.g. 'creeping') and the path of motion through a particle (e.g. 'across'). 
Giovanelli, M. 2014. Conceptual proximity and the experience of war in Siegfried Sassoon's 'A Working Party'. In C. Harrison, L. Nuttall, P. Stockwell \& W. Yuan (eds.), Cognitive grammar in literature, 145-159. Amsterdam: John Benjamins.

Harrison, C. 2017. Cognitive grammar in contemporary fiction. Amsterdam: John Benjamins.

Harrison, C. \& L. Nuttall. 2019. Cognitive grammar and reconstrual: Re-experiencing Margaret Atwood's ‘The Freeze-Dried Groom'. In B. Neurohr \& E. Stewart-Shaw (eds.), Experiencing fictional worlds,135-154. Amsterdam: John Benjamins.

Herman, D. 2013. Storytelling and the sciences of mind. Cambridge, MA: MIT Press.

Hipp, D. 2005. The poetry of shell shock: Wartime trauma and healing in Wilfred Owen, Ivor Gurney and Siegfried Sassoon. Jefferson, NC: McFarland.

Kövecses, Z. 2005. Metaphor in culture. Universality and variation. Cambridge: Cambridge University Press.

Kövecses, Z. 2008. Conceptual metaphor theory: Some criticisms and alternative proposals. Annual Review of Cognitive Linguistics 6. 168-184.

Kövecses, Z. 2015. Where metaphors come from: Reconsidering context in metaphor. New York, NY: Oxford University Press.

Lakoff, G. \& M. Johnson. 1999. Philosophy in the flesh: The embodied mind and its challenge to western thought. New York, NY: Basic Books.

Lambrou, M. 2014. Narrative, text and time: Telling the same story twice in the oral narrative reporting of 7/7. Language and Literature 23(1). 32-48.

Langacker, R. 1987. Foundations of cognitive grammar, Volume 1, Theoretical prerequisites. Stanford: Stanford University Press.

Langacker, R. 1991. Foundations of cognitive grammar, Volume 2, descriptive application. Stanford: Stanford University Press.

Langacker, R. 2007. Constructing the meaning of personal pronouns. In G. Radden, K-M. Köpcke, T. Berg \& P. Siemund (eds.), Aspects of meaning construction, 171-188. Amsterdam: John Benjamins.

Langacker, R. 2008. Cognitive grammar: A basic introduction. New York, NY: Oxford University Press.

Marchetti, G. 2006. A presentation of attentional semantics. Cognitive Processing 7(3). 163-194.

Moeyes, P. 1997. Siegfried Sassoon: Scorched glory: A critical study. New York, NY: St Martin's Press.

Nuttall, L. 2018. Mind style and cognitive grammar. London: Bloomsbury.

Polanyi L. 1981. Telling the same story twice. Text 1(4). 315-336.

Rivers, W.H. 1923. Conflict and dream. London: Routledge, Trench, Trübner and Co.

Rothenberg, A. 1990. Creativity and madness. Baltimore, MD: John Hopkins University Press.

Sassoon, S. 1930. Memoirs of an infantry officer. London: Faber and Faber.

Sassoon, S. 1983. Diaries 1915-1918, ed. Rupert Hart-Davis. London: Faber and Faber.

Sotirova, V. 2014. Production and intentionality. In P. Stockwell \& S. Whiteley (eds.), The Cambridge handbook of stylistics, 132-148. Cambridge: Cambridge University Press.

Stockwell, P. 2009. Texture: A cognitive aesthetics of reading. Edinburgh: Edinburgh University Press.

Stockwell, P. 2014. Atmosphere and tone. In P. Stockwell \& S. Whiteley (eds.), The Cambridge Handbook of Stylistics, 360-374. Cambridge: Cambridge University Press.

Stockwell, P. 2016. The texture of authorial intention. In J. Gavins \& E. Lahey (eds.), World building: Discourse in the mind, 147-163. London: Bloomsbury. 
Stockwell, P. 2017. The language of surrealism. London: Palgrave Macmillan.

Thorpe, M. 1966. Siegfried Sassoon: A critical study. London: Oxford University Press.

Ungerer, F. \& H. Schmid. 2006. An introduction to cognitive linguistics, 2nd edn. London: Longman.

Verspoor, M. 1996. The story of -ing: a subjective perspective. In M. Putz \& R. Dirven (eds.), The construal of space in language and thought, 417-454. Berlin: Walter de Gruyter.

Werth, P. 1999. Text worlds: Representing conceptual space in discourse. London: Longman.

West, D. 2017. Review of cognitive grammar in literature by Harrison et al. Language and Literature 26(1). 66-68.

Wimsatt, W.K. \& M.C. Beardsley. 1946. The intentional fallacy. The Sewanee Review 54(3). 468-488.

Winter, J. 2014. Beyond glory: First world war poetry and cultural memory. In S. Das (ed.), The Cambridge Companion to the Poetry of the First World War, 242-256. Cambridge: Cambridge University Press. 